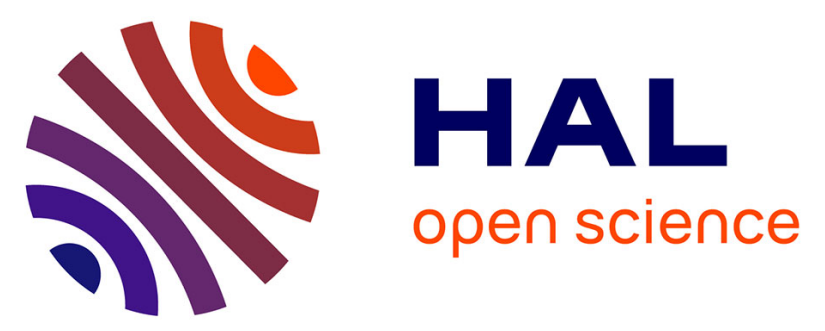

\title{
Tacrolimus: Does direct glucuronidation matter? An analytical and pharmacological perspective
}

C. Tron, A. Petitcollin, M.-C. Verdier, M. Rayar, J.-M. Beaurepaire, K.

Boudjema, E. Bellissant, F. Lemaitre

\section{To cite this version:}

C. Tron, A. Petitcollin, M.-C. Verdier, M. Rayar, J.-M. Beaurepaire, et al.. Tacrolimus: Does direct glucuronidation matter? An analytical and pharmacological perspective. Pharmacological Research, 2017, 124, pp.164-166. 10.1016/j.phrs.2017.03.027 . hal-01614704

HAL Id: hal-01614704

https://hal-univ-rennes1.archives-ouvertes.fr/hal-01614704

Submitted on 16 May 2018

HAL is a multi-disciplinary open access archive for the deposit and dissemination of scientific research documents, whether they are published or not. The documents may come from teaching and research institutions in France or abroad, or from public or private research centers.
L'archive ouverte pluridisciplinaire HAL, est destinée au dépôt et à la diffusion de documents scientifiques de niveau recherche, publiés ou non, émanant des établissements d'enseignement et de recherche français ou étrangers, des laboratoires publics ou privés. 


\section{Tacrolimus : does direct glucuronidation matter ? An analytical and pharmacological perspective.}

Camille Tron ${ }^{1,2,3}$ PharmD, Antoine Petitcollin ${ }^{1,2,3}$ PharmD, Marie-Clémence Verdier ${ }^{1,2,3}$ PharmD PhD, Michel Rayar ${ }^{3,4}$ MD, Jean-Marie Beaurepaire ${ }^{3,4}$ MD, Karim Boudjema ${ }^{3,4}$ MD PhD, Eric Bellissant ${ }^{1,2,3}$ MD PhD and Florian Lemaitre ${ }^{1,2,3}$ PharmD PhD

${ }^{1}$ Rennes University Hospital, Department of Clinical and Biological Pharmacology and Pharmacovigilance, Pharmacoepidemiology and Drug Information Center, 2 rue Henri le Guilloux 35033 Rennes, France.

${ }^{2}$ Rennes 1 University, Faculty of Medicine, Laboratory of Experimental and Clinical Pharmacology, 2 rue Henri le Guilloux 35033 Rennes, France.

${ }^{3}$ Inserm, CIC-P 1414 Clinical Investigation Center, 2 rue Henri le Guilloux 35033 Rennes, France.

${ }^{4}$ Rennes University Hospital, Unit of Hepato-biliary and digestive surgery, 2 rue Henri le Guilloux 35033 Rennes, France.

\section{Corresponding author:}

\section{Camille Tron}

Laboratoire de pharmacologie, Hôpital Pontchaillou

2 rue Henry le Guilloux, 35033, Rennes Cedex 9, France

Phone : +330299284280

Fax : +330299284184

Email : tron.camille@gmail.com

Conflict of interest statement:

The authors have no conflict of interest to declare.

\section{Fundings:}

This research did not receive any specific grant from funding agencies in public, commercial, or not-for-profit sectors. 


\section{Letter to the editor}

\section{To the editor:}

Tacrolimus, the gold standard of immunosuppressive treatment indicated to prevent graft rejection in solid organ recipients, is extensively metabolized. While impact of phase I metabolism on the drug pharmacokinetics has been widely discussed, little is known on its glucuronidation mediated by uridine diphosphate glucuronyltransferases (UGT). The impact of glucuronidation in the field of therapeutic drug monitoring might be underestimated mainly because glucuronide metabolite is presumed to be a non-active and short half-life drug.

As part of an on-going pharmacokinetic study conducted in our center (CYPTAC'H, NCT01388387) we performed extensive kinetic profiles of tacrolimus whole-blood concentrations in liver transplant recipient patients. Noteworthy, at least $15 \%$ of the profiles analyzed $(n=100)$ displayed a rebound in tacrolimus concentration after Tmax and beyond 5 hours post drug intake. Three representative profiles are shown in figure1A. Mechanism underlying this late increase of the drug concentration remains to be established. However, this particular pattern is typical of the one observed for a drug presenting an enterohepatic recirculation which could follow glucuronide metabolite hydrolysis in the gut lumen. Although evidences for this phenomenon in tacrolimus pharmacokinetics are scarce, the hypothesis cannot be ruled out. Actually, we would like to provide additional arguments in favor of the relevance of a glucuronidation pathway in tacrolimus pharmacokinetics. Indeed, in a study, aiming at measuring tacrolimus in bile samples using high performance liquid chromatography tandem mass spectrometry (LC-MS/MS), our team recently highlighted substantive in vivo formation of direct tacrolimus-glucuronide (tacro-G) [1]. First, we observed an interfering peak, co-eluted and unresolved with tacrolimus on its chromatogram (figure 1B). An interfering glucuronide metabolite was suspected, therefore we performed a hydrolysis of patient's bile samples with betaglucuronidase enzymes in order to transform any tacro-G to tacrolimus before the extraction procedure according to the usual strategy used in bioanalysis of glucuronides metabolites. The hydrolysis resulted in an elimination of the interfering peak (figure 1C) as well as a mean ( \pm sd) increase of tacrolimus response of $7.2 \pm 3.1$ fold ( $\mathrm{n}=6$ samples from incurred patients). Thus, the interfering peak observation was explained by a phenomenon of a back-conversion of the metabolite tacro-G to the parent molecule due to a dissociation of the glucuronide in the ionization source of the LC-MS/MS.

Production of tacro-G and its excretion in human bile has already been suggested some decades ago as a potential source of cross reactivity in the analysis of tacrolimus using immunoassay [2]. Here, we confirm in vivo tacro-G existence and emphasize that the metabolite may also be a hurdle to reach selectivity when using liquid chromatography based analytical method. Moreover, phenomenon of co-elution between glucuronide and parent drug and ion source dissociation have already been described with LC-MS/MS [3]. Thus, analytical method aiming at measuring tacrolimus in biological matrix should clearly assess the lack of interference between the parent drug and tacro-G to ensure accuracy of the measurement. 


\section{Letter to the editor}

In addition, the relative importance of direct-glucuronide compared to parent drug should be evaluated to determine whether this metabolic pathway of tacrolimus could have a clinical impact and play a role in the drug pharmacokinetics and pharmacological profiles.

First of all, tacro-G could contribute to tacrolimus inter-individual pharmacokinetics variability. One the one hand, tacro-

$\mathrm{G}$ released in bile could be dissociated into the aglycon by intestinal bacteria making it available for enterohepatic recirculation with a magnitude of the enterohepatic recirculation depending on patient's gut microbiota composition. This composition is highly variable and notably influenced by antibiotic drugs often co-administered with tacrolimus in transplant patients. On the other hand, human betaglucuronidases are found in many biological liquid and tissues, then the hydrolysis of tacro-G in the body could modify the drug distribution and its clearance. Consequently, a local or systemic prolongation of its effect could be expected. Not to mention that polymorphisms in human betaglucuronidase genes have been reported to increase the inter-individual variability in the drug exposure [4].

Besides, glucuronides production is controlled by UGTs whom genes polymorphisms have been described. Glucuronide/parent drug ratio can then be influenced by this phenomenon leading to inter-patient variability. It was also demonstrated that UGT1A4 was involved in vitro in tacrolimus glucuronide formation and the gene coding for this enzyme has been shown to exhibit polymorphisms modulating its expression [5]. UGTs can also be inhibited and/or induced by numerous drugs or environmental factors thus increasing the variability of this metabolic pathway. However, to date little work has been conducted on such a source of pharmacokinetic variability.

Furthermore, the contribution of tacro-G to tacrolimus overall immunosuppressive effect is unknown. Indeed, several examples of active direct glucuronide metabolites exist. The best recognized of these examples is 6-O-glucuronide morphine which is an active metabolite of the parent drug morphine. Thus, one cannot exclude tacro-G to exert an immunosuppressive effect and/or to contribute to the adverse events attributed to tacrolimus. At least one metabolite of tacrolimus (31-demethyl-tacrolimus) has been shown to have an immunosuppressive effect. Then, one cannot exclude that part of the immunosuppressive effect could be due to other metabolites and particularly the less studied glucuronides. This could maybe explain at least partially the high degree of variability in the immunosuppressive effect.

In conclusion, little is known on drug metabolism through glucuronidation pathway. This pathway is not commonly explored. However, it might have critical impact for drugs with narrow therapeutic range such as tacrolimus. We provided consistent evidences from two independent studies that direct glucuronide of tacrolimus formation might be a cause on concern. On the one hand it interferes with parent drug during LC-MS/MS analysis and on the other hand, one should not underestimate the potential role of glucuronide on the drug pharmacokinetic profile. Therefore, the role of direct glucuronide of tacrolimus should be further investigated.

Keywords: Tacrolimus; glucuronide; metabolism; pharmacokinetics; mass spectrometry 


\section{Letter to the editor}

\section{References:}

[1] C. Tron, M. Rayar, A. Petitcollin, J.-M. Beaurepaire, C. Cusumano, M.-C. Verdier, P. Houssel-Debry, C. Camus, K. Boudjema, E. Bellissant, F. Lemaitre, A high performance liquid chromatography tandem mass spectrometry for the quantification of tacrolimus in human bile in liver transplant recipients, J. Chromatogr. A. 1475 (2016) $55-63$. doi:10.1016/j.chroma.2016.10.075.

[2] I. Firdaous, R.K. Verbeeck, A. Hassoun, J.M. Langrehr, P.E. Wallemacq, Excretion of tacrolimus glucuronides in human bile, Eur. J. Drug Metab. Pharmacokinet. 22 (1997) 217-221.

[3] J.-N. Mess, E.-R. Bérubé, M. Furtado, F. Garofolo, A practical approach to reduce interference due to in-source collision-induced dissociation of acylglucuronides in LC-MS/MS, Bioanalysis. 3 (2011) 1741-1751. doi:10.4155/bio.11.156.

[4] B. Sperker, J.T. Backman, H.K. Kroemer, The role of beta-glucuronidase in drug disposition and drug targeting in humans, Clin. Pharmacokinet. 33 (1997) 18-31.

[5] I. Laverdiere, P. Caron, M. Harvey, E. Levesque, C. Guillemette, In Vitro Investigation of Human UDPGlucuronosyltransferase Isoforms Responsible for Tacrolimus Glucuronidation: Predominant Contribution of UGT1A4, Drug Metab. Dispos. 39 (2011) 1127-1130. doi:10.1124/dmd.111.039040. 

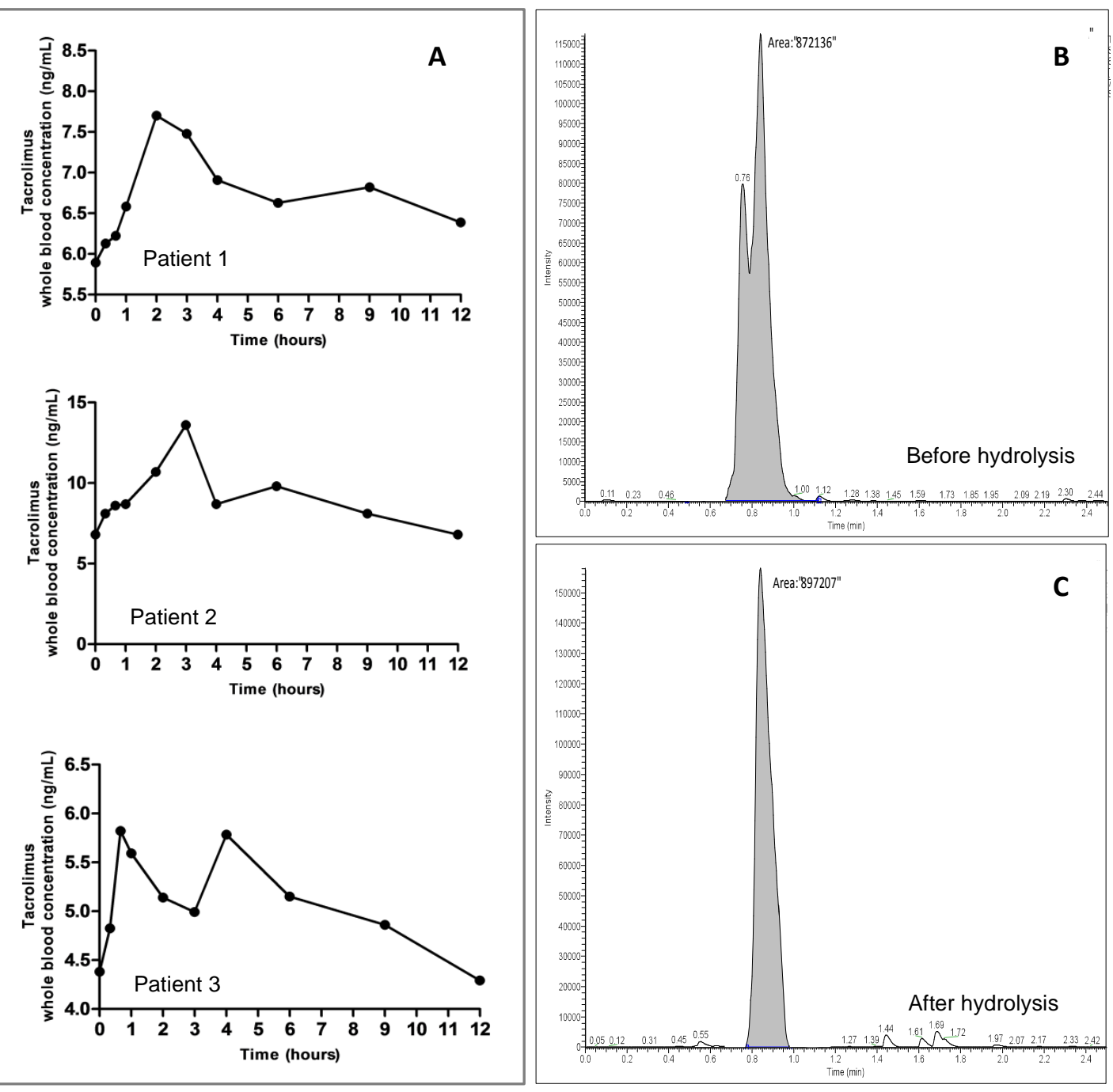

Figure 1: Representative pharmacokinetics profiles of tacrolimus in whole blood from liver transplant recipients displaying a rebound in tacrolimus concentrations (A). Representative LC-MS/MS chromatograms of tacrolimus (for tacrolimus m/z MS/MS transition) analysed in an incurred patient bile sample. An un-resolved peak, coming from a metabolite back conversion to tacrolimus in the MS system source, was eluted with tacrolimus (B). After hydrolysis before extraction with beta-glucuronidases enzymes, the metabolite was extensively converted to tacrolimus and only a single peak was detected by the MS system (C). 